ORIGINAL ARTICLE

\title{
Three Consecutive Waves of Cholera Outbreak in Ethiopia (2015- 2017): Explanatory Analysis
}

\author{
Neamin Tesfay ${ }^{1 *}$, Mengistu Biru ${ }^{1}$
}

\footnotetext{
OPEN ACCESS

Citation: Gebreyesus Neamin, Tesema Mengistu. Three Consecutive Waves of Cholera Outbreak in Ethiopia (20152017): Explanatory Analysis. Ethiop J Health Sci.2020;30(4):469. doi:http:// dx.doi.org/ 10.4314/ejhs.v30i4.2

Received: December 13, 2019

Accepted: February 4, 2020

Published: July 1, 2020

Copyright: (C) 2020 Gebreyesus Neamin, et al. This is an open access article distributed under the terms of the Creative Commons Attribution License, which permits unrestricted use, distribution, and reproduction in any medium, provided the original author and source are credited.

Funding: Nil

Competing Interests: The authors declare that this manuscript was approved by all authors in its form and that no competing interest exists.

Affiliation and Correspondence:

${ }^{1}$ Center of Public Health Emergency Management, Ethiopian Public Heath Institutes, Addis Ababa, Ethiopia

*Email:

neamintesfaye2123@gmail.com
}

\section{ABSTRACT}

BACKGROUND: Cholera is an acute epidemic infectious disease. It is characterized by watery diarrhea, extreme loss of fluid and electrolytes, and severe dehydration. Ethiopia faced three consecutive waves of cholera outbreaks: nearly all regional states and city administrations, with the exception of one, were affected. The study was conducted with the aim of describing the epidemiology of the outbreak within the defined three years.

METHODS: Secondary data review was conducted along with explanatory methods of analysis individual patient data reported from different corners of the country in the time period of 2015 2017. Cases were identified using the case definition stated on the national guideline for cholera control in Ethiopia.

RESULT: A total of 36,154 cholera cases and 246 deaths were reported (overall case-fatality rate [CFR=0.7\%] affecting all regions of the country except Gambella). The outbreak began in 2015 with 238 cases and 2 deaths [CFR=0.8\%]. The largest outbreak during the period under this study occurred in 2016, with 29,338 cases and 188 deaths [CFR=0. 6\%]. Following a decline in disease occurrence, the country experienced a resurgence of epidemic cholera during 2017 (6,578 cases and 56 deaths; CFR, 0.9\%), which declined rapidly to a few cases. AR was higher in males [37.01/100,000] and persons in the age group of 15-44years [44.10/100,000] in 2016.

CONCLUSION: The outbreak affected nearly every corner of the country. Taken together, the epidemiological trends of cholera in Ethiopia showed an annual decrement in frequency and length of outbreaks during the 3 years under review. The recent decreases in cholera case counts may reflect cholera control measures put in place by public health authorities of the national Ministry of Health.

KEYWORDS: Cholera, Ethiopia, Outbreak, Consecutive

\section{INTRODUCTION}

Cholera is an acute bacterial enteric disease characterized by its severe form by sudden onset, profuse painless, watery stool (ricewater stool), nausea and profuse vomiting early in the course of 
illness (1). In untreated cases, rapid dehydration, acidosis, circulatory collapse, hypoglycemia in children, and renal failure can rapidly lead to death $(2,3)$. In most cases, the infection is asymptomatic or causes mild diarrhea, especially with organisms of the El Tor biotype; asymptomatic carriers can transmit the infection (4). In severe dehydrated cases (cholera Gravis), death may occur within a few hours, and the case-fatality rate may exceed $50 \%$. However, with proper and timely rehydration, this can be less than $1 \%(5)$. Cholera is a severe, acute, dehydrating diarrhea that can kill children and adults in less than 12 hours (4).

The Diagnosis of cholera is confirmed by isolating Vibrio cholerae of the serogroup $\mathrm{O} 1$ or O139 from feces. V. Cholerae grows well on standard culture media, the most widely used of which is thiosulphate citrate bile -salt sucrose agar. The strains are further characterized by $\mathrm{O} 1$ and $\mathrm{O} 139$ specific antisera (6).

Globally, an estimated 3 - 5 million cholera cases and 28,000-150,000 deaths occur yearly $(7,8)$. Recent estimations also fall within this range with Cholera killing an estimated 95, 000 persons per year and sickening more than 2.86 million people annually (9). It is the main public health problem in South Asia, particularly the Indian sub-continent while it has endemicepidemic status in sub-Sahara Africa (10). Except for the United States of America, cholera cases were reported both sporadically as well as at endemic levels in countries and dependent territories in North America (11). On the other hand, cases reported from the European Union were mostly imported from countries where cholera is endemic or an outbreak was ongoing (11). From North America, a high number of cases were reported from Haiti, 754,373 cases and 8,964 deaths reported. Similarly, Dominican Republic reported 32,064 cases and 472 deaths with a case fatality of $1 \%$ during the year 2011 2017 (12). In Yemen, which is located in the Gulf of Aden, astonishingly a high number of cholera cases and deaths have been recorded with above 500,000 cases reported in just a single year (2016-2017) while the number of deaths reported up until July 2017 exceeded 1,800 (13). In Africa, Somali reported 129,324 cases and 1,228 deaths just from 2016-2017.
Tanzanian reported 2,511 cases and 390 deaths with a total case fatality rate of $14 \%$ from 2015 2017 (11).

In Ethiopia, it was indicated that there was cholera epidemic in 1990 which persisted with recrudescence of cases till 1998 (14). Moreover, from July 2008 to June 2009, there were a total of 9,485 cases and 193 deaths (with a casefatality rate of $2.0 \%$ ) of cholera in six regions including the capital Addis Ababa (15). Currently, in Ethiopia, 5.9 million people are estimated to be living in cholera hot spot areas, which are specific and relatively small areas where the cholera burden is most concentrated and that plays a central role in the spread of cholera (16). Besides, Ethiopia is surrounded by countries like Somalia and South Sudan, which are currently unstable and more favorable for the cholera outbreak. On the other hand, due to climatic change, Ethiopia also faced consecutive waves of cholera outbreak nationwide in the last three years (17). However, burden and severity were varying from year to year; it was affected almost in all regions and city administrations of the country.

Currently, in Ethiopia, cholera is under control even if sporadic and unrelated cases were reported from the regions. The objective of this study was to assess the epidemiology of the outbreak in the past three years in Ethiopia.

\section{METHODS}

Study area: Ethiopia is located at $9.1450^{\circ} \mathrm{N}$, $40.4897^{\circ}$ E. Ethiopia has nine regions and two city administrations. According to the latest United Nations estimates, the current population is estimated at $100,613,986$ with an annual growth of $2.9 \%$ and in 2017 contributed to $1.39 \%$ of the total world population (18). The total land area is nearly $1,100,000$ square kilometers (19), with the population density reaching 105 people per sq. $\mathrm{km}$ of land area in 2017 (20). Ethiopia has nine regions and two city administrations in the current federal system arrangement. The study was conducted from June 29-July 17, 2019.

Study design: A secondary data review was conducted with explanatory methods of analysis from the collected line list reported from 
different regions and city administrations of the country from August 2015 up to July 7, 2017.

Case definition: Suspected case

A case of cholera should be suspected when:

o In an area where the disease is not known to be present, a patient aged 5 years or more develops severe dehydration or dies from acute watery diarrhea;

- In an area where there is a cholera epidemic, a patient aged 5 years or more develops acute watery diarrhea, with or without vomiting (21).

In the health post and at community levels, a suspected cholera case can be defined as follows: any person 5 years of age or more with profuse acute watery diarrhea and vomiting.

Probable cases: Probable cases refer to suspected cases in which Vibrio cholerae $\mathrm{O} 1$ or O139 has been isolated from their stool using the cholera rapid diagnosis tool (RDT) (21.

Confirmed case: Confirmed case refers to a suspected case in which Vibrio cholerae O1 or O139 has been isolated from stool using culture (21).

Population under surveillance: This refers to all populations lives in the country. The number of populations mentioned in the document is used based on the projection of the Ethiopian Central Statics Agency (22).

Data type and source: Secondary data were used from the Ethiopian Public Health Institute (EPHI) specifically from the Center for Public Health Emergency Management.

Data analysis and presentation: Data were analyzed using Tableau 10.4 and Arc GIS 10.5.

Ethical clearance: A formal letter was submitted to the data manager at EPHI to access the data. Ethical clearance was obtained from the data manager of EPHI. For the sake of confidentiality, personal identifiers were not used in the study. Since the study used secondary data sources, consent and other ethical measures were not applicable.

\section{RESULTS}

A total of 36,154 cholera cases were reported from all regions and city administrations in Ethiopia, except Gambella region. Of the cases, $29,501(81.50 \%)$ were from three regions and one city administration of the country; namely Somalia, Oromia, Amhara, and Addis Ababa as depicted in (Table 1).

Table 1: Distribution of cholera case by place in Ethiopia from 2015-2017

\begin{tabular}{lrrr}
\hline & Frequency & Percentage & Cumulative percentage \\
\hline Somali & 8547 & $23.60 \%$ & $23.60 \%$ \\
Addis Ababa & 8110 & $22.40 \%$ & $46.00 \%$ \\
Oromia & 7318 & $20.20 \%$ & $66.20 \%$ \\
Amhara & 5526 & $15.30 \%$ & $81.50 \%$ \\
Tigray & 3346 & $9.30 \%$ & $90.80 \%$ \\
Afar & 1609 & $4.50 \%$ & $95.30 \%$ \\
SNNPR & 949 & $2.60 \%$ & $97.90 \%$ \\
B/Gumuz & 426 & $1.20 \%$ & $99.10 \%$ \\
Harari & 273 & $0.80 \%$ & $99.90 \%$ \\
Dire Dawa & 50 & $0.10 \%$ & $100.00 \%$ \\
Gambella & 0 & $0.00 \%$ & $100.00 \%$ \\
Grand total & 36,154 & $100 \%$ &
\end{tabular}

DOI: http://dx.doi.org/10.4314/ejhs.v30i4.2 
Distribution by person and time: Men were more affected with a maximum attack rate of $37.01 / 100,000$, and those who were between the ages of 15-44 years were also more affected with an attack rate of rate 44.10/100000 in 2016 . In 2016，29,338(81\%) cholera cases were reported with attack rate 31.9/100000: Regionwise, four regions of the country reported $22,989(78 \%)$ cases in 2016. The detailed level of attack rate is shown in Table 2. The epidemic curve (Figure 1) shows that the outbreak began rapidly on week $35 / 2015$ when 3 cases were reported. There were 5 peaks during the outbreak in the period under study (2015 2017). However, all of the peaks occurred in 2016: in week 29(1,669 cases), week 31(1,450 cases), week $32(1,570$ cases $)$, week 33(2,203 cases), and week 36(1,525cases).

Table 2: Distribution of attack rate of cholera case by a person and place in Ethiopian from 2015-2017

\begin{tabular}{|c|c|c|c|c|c|c|c|c|c|}
\hline \multirow[t]{2}{*}{ Category } & \multicolumn{3}{|c|}{ Population } & \multicolumn{3}{|c|}{ Number of cases } & \multicolumn{3}{|c|}{ Attack rate $/ \mathbf{1 0 0 0 0 0}$} \\
\hline & 2015 & 2016 & 2017 & 2015 & 2016 & 2017 & 2015 & 2016 & 2017 \\
\hline \multicolumn{10}{|l|}{ Sex } \\
\hline Male & $45,879,613$ & $46,963,870$ & $49,232,195$ & 122 & 17,379 & 3334 & 0.27 & 37.01 & 6.77 \\
\hline Female & $44,080,412$ & $45,122,150$ & $47,301,521$ & 116 & 11,959 & 3244 & 0.26 & 26.5 & 6.86 \\
\hline \multicolumn{10}{|l|}{ Age group } \\
\hline$<5$ & $24,019,327$ & $24,586,967$ & $25,774,502$ & 71 & 2,112 & 879 & 0.3 & 8.59 & 3.41 \\
\hline 5_14 & $39,762,331$ & $40,702,021$ & $42,667,902$ & 103 & 17,302 & 2,826 & 0.26 & 42.51 & 6.62 \\
\hline $15-44$ & $13,494,004$ & $13,812,903$ & $14,480,057$ & 39 & 6086 & 1461 & 0.29 & 44.1 & 10.09 \\
\hline $45+$ & $12,684,364$ & $12,984,129$ & $13,611,254$ & 25 & 3838 & 1412 & 0.2 & 29.56 & 10.37 \\
\hline \multicolumn{10}{|l|}{ Region } \\
\hline Addis Ababa & $3,273,000$ & $3,352,000$ & $3,471,792$ & 3 & 8,104 & 3 & 0.1 & 241.8 & 0.1 \\
\hline Afar & $1,723,007$ & $1,769,002$ & $1,911,039$ & 2 & 1,363 & 244 & 0.1 & 77 & 12.8 \\
\hline Amhara & 20399004 & 20769985 & $21,993,893$ & 0 & 4,435 & 1091 & 0 & 21.4 & 5 \\
\hline B/Gumuz & 1005001 & 1033999 & $1,065,966$ & 0 & 394 & 32 & 0 & 38.1 & 3 \\
\hline Dire Dawa & 440,000 & 453,000 & 466,000 & 0 & 50 & 0 & 0 & 11 & 0 \\
\hline Gambella & 409,002 & 422,002 & 435,999 & 0 & 0 & 0 & 0 & 0 & 0 \\
\hline Harari & 232000 & $2,400,00$ & 246000 & 0 & 273 & 0 & 0 & 113.8 & 0 \\
\hline Oromia & $33,691,991$ & $34,575,008$ & 36573613 & 127 & 5,372 & 1819 & 0.4 & 15.5 & 5 \\
\hline SNNPR & $18,276,012$ & $18,719,008$ & 19549496 & 0 & 941 & 8 & 0 & 5 & 0 \\
\hline Somali & $54,529,94$ & $5,598,002$ & 5694291 & 106 & 5,078 & 3363 & 1.9 & 90.7 & 59.1 \\
\hline Tigray & $50,559,99$ & $5,151,998$ & 5123610 & 0 & 3,328 & 18 & 0 & 64.6 & 0.4 \\
\hline Total population & $89,960,025$ & $92,086,020$ & $96,533,716$ & 238 & 29,338 & 6578 & 0.3 & 31.9 & 6.8 \\
\hline
\end{tabular}


Three Consecutive Waves of Cholera Outbreak...

Gebreyesus N. et al.

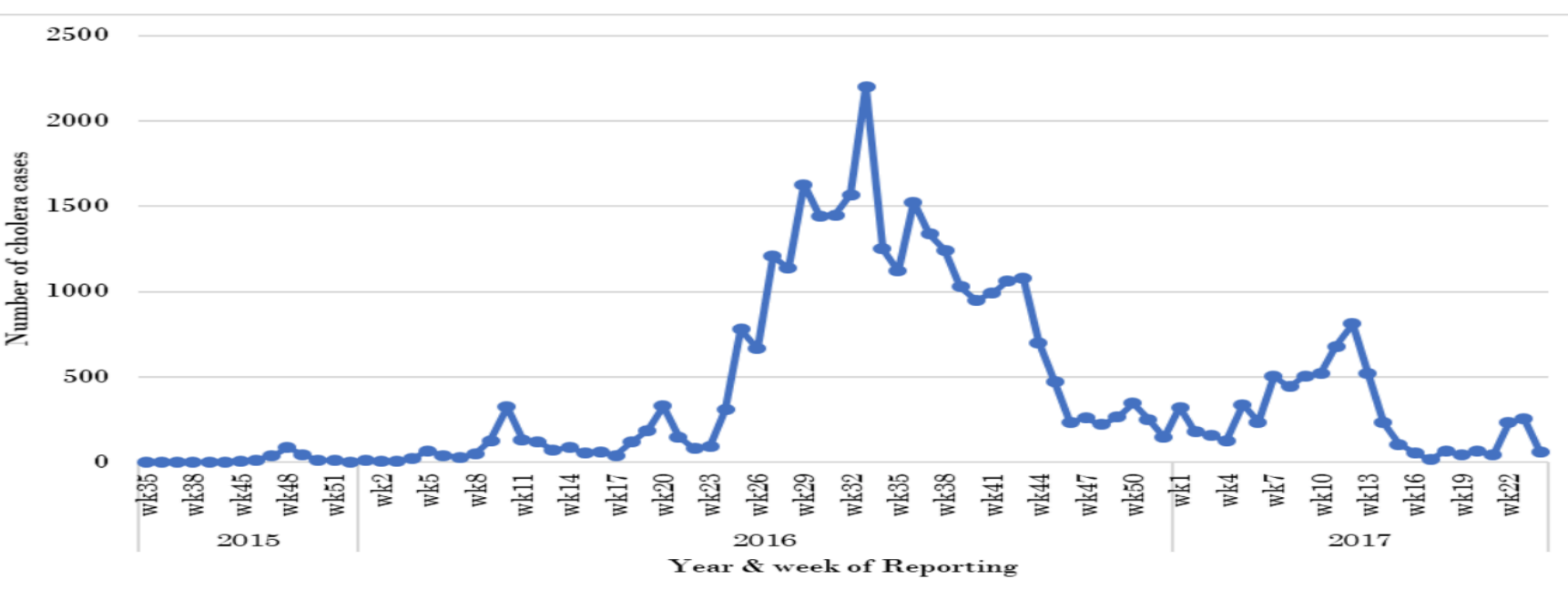

Figure 1: The trend of cholera outbreak by WHO epi week from 2015-2017

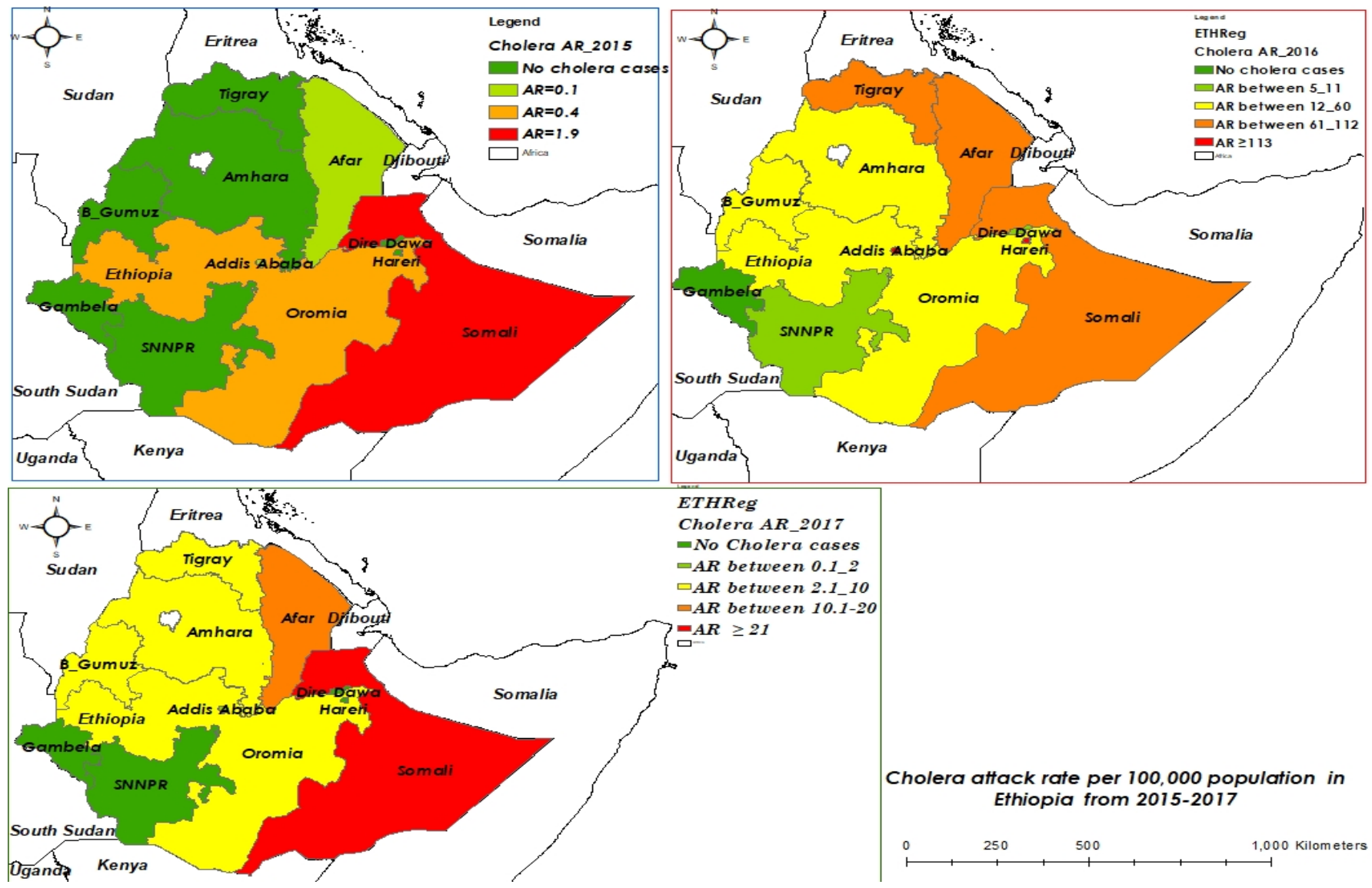

Figure 2: Level of cholera attack rate per 100000 populations in Ethiopia from 2015-2017

DOI: http://dx.doi.org/10.4314/ejhs.v30i4.2 
Regarding case management, from total cases, $13,176(36 \%)$ were classified as severely dehydrated. A total of 246 deaths were recorded which makes the case fatality rate of $0.8 \%$ within the defined period of time as described in Table 3. Regarding the classification of the case, only
$193(0.5 \%)$ cases were confirmed and 3,861 $(10.7 \%)$ were treated as suspected cholera cases. However, the remaining cases were treated as probable cases of cholera. The details are summarized in Table 4.

Table 3: pattern of case fatality by sex, age group and region in Ethiopia from 2015-2017

\begin{tabular}{|c|c|c|c|c|c|c|c|c|c|}
\hline \multirow[t]{3}{*}{ Category } & \multicolumn{3}{|c|}{ No. of Cholera Cases } & \multicolumn{3}{|c|}{ No. of Cholera Death } & \multicolumn{3}{|c|}{ CFR (\%) } \\
\hline & 2015 & 2016 & 201 & 2015 & 2016 & 2017 & 2015 & 2016 & 201 \\
\hline & & & 7 & & & & & & 7 \\
\hline \multicolumn{10}{|l|}{ Sex } \\
\hline Male & 122 & 17379 & $\begin{array}{r}333 \\
4\end{array}$ & 2 & 113 & 31 & 1.64 & 0.65 & 0.93 \\
\hline Female & 116 & 11959 & $\begin{array}{r}324 \\
4\end{array}$ & 0 & 75 & 25 & 0.00 & 0.63 & 0.77 \\
\hline \multicolumn{10}{|l|}{ Age group } \\
\hline$<5$ & 71 & 2112 & 879 & 0 & 22 & 10 & 0.00 & 1.04 & 1.14 \\
\hline 5_14 & 25 & 3838 & $\begin{array}{r}141 \\
2\end{array}$ & 0 & 24 & 9 & 0.00 & 0.63 & 0.64 \\
\hline 15_44 & 39 & 6086 & $\begin{array}{r}146 \\
1\end{array}$ & 2 & 79 & 19 & 5.13 & 1.30 & 1.30 \\
\hline $45+$ & 103 & 17302 & $\begin{array}{r}282 \\
6\end{array}$ & 0 & 63 & 18 & 0.00 & 0.36 & 0.64 \\
\hline \multicolumn{10}{|l|}{ Region } \\
\hline Addis Ababa & 3 & 8104 & 3 & 0 & 15 & 0 & 0 & 0.2 & 0 \\
\hline Afar & 2 & 1363 & 244 & 0 & 11 & 4 & 0 & 0.8 & 1.6 \\
\hline Amhara & 0 & 4435 & $\begin{array}{r}109 \\
1\end{array}$ & 0 & 0 & 17 & 0 & 0 & 1.6 \\
\hline B/Gumuz & 0 & 394 & 32 & 0 & 22 & 6 & 0 & 5.6 & 18.8 \\
\hline Dire Dawa & 0 & 50 & 0 & 0 & 0 & 0 & 0 & 0 & 0 \\
\hline Gambella & 0 & 0 & 0 & 0 & 0 & 0 & 0 & 0 & 0 \\
\hline Harar & 0 & 273 & 0 & 0 & 0 & 0 & 0 & 0 & 0 \\
\hline Oromia & 127 & 5372 & $\begin{array}{r}181 \\
9\end{array}$ & 1 & 60 & 5 & 0.8 & 1.1 & 0.3 \\
\hline SNNPR & 0 & 941 & 8 & 0 & 10 & 0 & 0 & 1.1 & 0 \\
\hline Somali & 106 & 5078 & $\begin{array}{r}336 \\
3\end{array}$ & 1 & 28 & 24 & 0.9 & 0.6 & 0.7 \\
\hline Tigray & 0 & 3328 & 18 & 0 & 42 & 0 & 0 & 1.3 & 0 \\
\hline Grand Total & 238 & 29338 & $\begin{array}{r}657 \\
8 \\
\end{array}$ & 2 & 188 & 56 & 0.8 & 0.6 & 0.9 \\
\hline
\end{tabular}


Table 4: Distribution cholera case by laboratory confirmation in Ethiopia from 2015-2017

\begin{tabular}{|c|c|c|c|c|}
\hline Laboratory confirmation & $\begin{array}{l}\text { Frequenc } \\
\mathbf{y}\end{array}$ & $\begin{array}{l}\text { \# Positive } \\
\text { cases }\end{array}$ & $\begin{array}{c}\text { (\%) Positive } \\
\text { cases } \\
\text { from total cases }\end{array}$ & $\begin{array}{l}\text { Positive } \\
\text { rate }\end{array}$ \\
\hline RDT & 4256 & 3861 & $10.7 \%$ & $90.7 \%$ \\
\hline Culture & 221 & 193 & $0.5 \%$ & $87.3 \%$ \\
\hline $\begin{array}{l}\text { Total case diagnosis by (RDT \& } \\
\text { culture) }\end{array}$ & 4477 & 4054 & 11.2 & $90.6 \%$ \\
\hline NA & 31677 & - & $87.6 \%$ & - \\
\hline Total Reported cases & 36154 & & $100.0 \%$ & \\
\hline
\end{tabular}

$\mathrm{NA}=$ (No laboratory confirmation)

\section{DISCUSSION}

The study aimed to describe the overall situation of the cholera outbreak in Ethiopia. Ethiopia was affected by consecutive waves of cholera outbreaks from 2015 to 2017. However, it was not reported to the WHO due to fear of economic repercussions resulting from trade restrictions and decreased tourism (23). Besides, Ethiopia has signed an agreement under International Health Regulations (IHR) to notify such an event to WHO according to the defined criteria. Yet, Ethiopia failed to notify the event via the assigned international health regulation (IHR) focal to WHO (24).

Generally, overcrowding, inadequate water both in quantity and quality, inadequate personal hygiene, poor washing facilities, poor sanitation practice, and inadequate food safety were the major contributing factors identified for the spread of cholera outbreak in different places (21). Every corner of the country was affected by the outbreak except the Gambella region. The number of cases was higher in four regions of the country by reporting more than $80 \%$ cases within the three years of the outbreak; namely, Somali region, Addis Ababa City Administration, Oromia and Amhara regions. From the reported cholera cases, the highest number of cholera cases was observed in Somali region, and the lowest was in Dire Dawa City administration. The burden had similarities with the outbreak reported in west Bengal India (25).
The analysis of the demographic characteristics of patients showed that males and persons aged 15-44 years were more affected as compared to the remaining categories. This might be explained by the fact that men and people in the age group of between 15-44 years tended to be more mobile and were more likely to eat and drink outside the home. This finding was supported by a study conducted in the Oromia region, Ethiopia, and Niger $(23,26)$.

The analysis of the geographical distribution of cases during 2015-2017 shows that some geographic areas have experienced prolonged and repeated outbreaks, whereas other areas were affected sporadically. In 2015, the burden and the distribution of cases were limited to small geographical areas: with an average attack rate of $0.3 / 100,000$ population with a range of (0.11.9)/100,000. However, in 2016, nearly 30,000 cases were reported from all regions and city administrations of the country, except Gambella region. The capital Addis Ababa took the lead by reporting $8,107(27.4 \%)$ cases followed by Oromia and Somali regions which reported $5,372(18.3 \%)$ and 5,078(17.3\%) cases respectively, from the total cases reported in 2016. The average attack rate for 2016 was $31.9 / 100,000$ with a range of (5.0-241.8) $/ 100,000$ population with the minimum attack rate observed in Southern Nations and Nationalities and People's (SNNP) region while the maximum AR was observed in Addis Ababa City Administration. In 2017, the number of cholera cases sharply declined as compared to

DOI: http://dx.doi.org/10.4314/ejhs.v30i4.2 
2016; the outbreak was not reported in Harari region, Dire Dawa City Administration, and Gambella region.

The outbreak reports begun from WHO EPIweek 35 in 2015, and it was initially limited to remote parts of Somali and Oromia regions. However, following the rainy season, the number of cases began to increase and the outbreak expanded to the remaining part of the county. The level of attack rate varies for region to region with the year of the report. For instance, the attack rate was higher in Addis Ababa City Administration and Harari region with a rate of 241.8 and 113.8 per 100,000 populations respectively in 2016 . This might be explained by the high population destiny in these areas which facilitates person-to-person transmission (27).

Quality of management and level of awareness regarding the illness is determined by dehydration status and case fatality rate. The CFR ranged from $0.62-1.52 \%$ in the reported three years and the highest rates were observed in 2017. This might be explained by reduced commitment and a decline in political attention compared to the previous year. On the other hand, the lowest CFR was observed in 2016 compared to the remaining outbreak reported years; even if a high number of cholera cases were reported.

Moreover, region-wise, the highest CFR was observed in the Somali region while the lowest was in the Oromia region in 2015. This might be explained by relatively weaker access to healthcare in Somalia region which has many pocket areas which are inaccessible by road.

In 2016, the lowest CFR was seen in the capital Addis Ababa, and the highest CFR was reported from Benishangul Gumuz region. This might be explained by Addis Ababa is the capital city of Ethiopia which has relatively full availability of basic infrastructures and health professionals as compared to the remaining other regions (28).

In 2017, the number of cholera cases and deaths fell sharply as compared to 2016. However, the highest CFR was observed with a rate of $18.8 \%$ in Benishangul Gumuz region at the end of the outbreak. One of the explanations may be because of staff exhaustion and poor case management (21).

The overall case fatality rate was $0.7 \%$ which is within the acceptable range of CFR (29). Moreover, it is lower as compared to other countries like South Sudan, Democratic Republic of Congo and Nigeria (30,31). This may be due to good management of cases, decentralization of cholera treatment unit and ensuring the availability of supply along with enhancing prevention and control activity.

During treatment, 13,176(36\%) cases were severely dehydrated which may indicate low level of awareness among cases about the illness, or it may due to misclassification of dehydration status. From the total reported cases within the defined period of time, only 4,477(12.4\%) cases were diagnosed using laboratory: from them, only $193(0.5 \%)$ cases were confirmed by the gold standard which is below the expected level. However, not every reported case has to be confirmed in the laboratory. If most patients have signs and symptoms compatible with the working diagnosis, and, perhaps, $15 \%$ to $20 \%$ are laboratory-confirmed, countries do not need more confirmation (32). The finding was similar to the studies conducted in Niger (33) and Kenya (34) where very low proportion of bacteriologically confirmed cases were observed which limits the reliability of information available to guide prevention and control strategies. Although laboratory capacity to support routine surveillance has been weak, improvements were observed in microbiological testing capacity and laboratory data management overtime on using both rapid diagnostics tests and culture. The laboratory component of the public health surveillance should continue to be strengthened and supported at the health facility, district, provincial and national levels (35).

The present analysis has provided a review of cholera in Ethiopia over the defined period. However, the study has the following limitations. On the one hand, only health facility deaths were reported, which affect the estimation of CFR as it does not take deaths that occurred outside facilities among communities into account. Additionally, microbiological confirmation of most cases was unknown and can influence the

DOI: http://dx.doi.org/10.4314/ejhs.v30i4.2 
distribution of the case. Due to such limitations, the burden of cholera has not yet been well characterized.

A cholera outbreak is becoming a major public health problem in Ethiopia for the last few years. It needs both short- and long-term evidence-based interventions. In this regard, advanced predictive epidemiological modeling like Generalized Additive Modeling (GAM) and Multiple Linear Regression (MLR) approaches would enable the country in quantifying the influence of climate and socioeconomic variables in explaining the spatial and temporal variability of cholera is needed.

In conclusion, the outbreak was not notified to WHO based on the decision instrument set by International Health Regulations. The outbreak affected almost all regions and city administrations of the country with a high attack rate and low case fatality in the central part of the country whereas the reverse was observed in remote parts of the country. Besides, the outbreak highly affected the working-age group. A small number of cases were confirmed by the laboratory during the period of the outbreak. As a way forward, improving the quality of management across the country with maximum utilization of laboratory confirmation is recommended. Also, the level of preparedness and commitment for managing and controlling the outbreak should be similar regardless of the status of the outbreak; the level of commitment can be maintained by training health workers, employing a rotation-based system that helps avoid burn out and avail different incentive mechanism such as risk allowance and public recognition, because high CFR was seen within a smaller number of cases at the termination of the outbreak. Since cholera is not endemic to Ethiopia alone, it is mandatory to report with adherence to International Health Regulations.

\section{ACKNOWLEDGMENTS}

We would like to acknowledge Ethiopian Public Health Institute (EPHI) for the support during the study by availing access to use the data

\section{REFERNECES}

1. Ajayi A, Smith SI. Recurrent cholera epidemics in Africa: which way forward? A literature review. Infection. $2019 \quad$ Jun;47(3):341-9. https://doi.org/10.1007/s15010-019-01292-8.

2. World Health Organization. Guidelines for cholera control. World Health Organization; 1993

3. Division of Communicable and Vector Borne Diseases, Disease Outbreak Management Unit. Kenya cholera guideline - Google Search [Internet]. [cited 2020 Jan 27]. Available forms https://tinyurl.com/y99png3b

4. Cravioto A, Lanata CF, Lantagne DS, Nair GB. Final Report of the Independent Panel of Experts on the Cholera Outbreak in Haiti. United Nations. $1-32$

5. Rapid Risk Assessment: Cholera outbreak in Algeria, 2018 | 7 September 2018 - Algeria [Internet]. Relief Web. [cited 2020 Jan 27]. Available from: https://tinyurl.com/y7bh4lkg

6. Heymann DL: Control of communicable disease manual 18th edition. Washington, D.C.: American Public Health Association; 2004.

7. Dan-Nwafor CC, Ogbonna U, Onyiah P, Gidado S, Adebobola B, Nguku P, Nsubuga P. A cholera outbreak in a rural north central Nigerian community: an unmatched case-control study. BMC public health. 2019 Dec 1;19(1):112.

8. Ohene S-A, Klenyuie W, Sarpeh M. Assessment of the response to cholera outbreaks in two districts in Ghana. Infectious Diseases of Poverty. 2016 Nov 2;5(1):99.

9. Legros D. Global cholera epidemiology: opportunities to reduce the burden of cholera by 2030. The Journal of infectious diseases. 2018 Oct 15;218(suppl_3): S137-40.

10. Akyala Ishaku A, Shadrack BE, Ajumobi O, Olayinka A, Nguku P. Investigation of cholera outbreak in an urban north central Nigerian community: the Akwanga experience. Public Health Res. 2014; 4:7-12.

11. Rapid risk assessment: Increase of cholera cases in the Horn of Africa and the Gulf of Aden - risk for EU/EEA citizens, 23 May 2017 [Internet]. European Centre for Disease Prevention and Control. 2017 [cited 2019 Jul 31]. Available from: https://tinyurl.com/ydauwtrj

12. 4 May 2017: Cholera - Epidemiological Update PAHO/WHO | Pan American Health Organization [Internet]. [cited July 31, 2019]. Available from: https://tinyurl.com/ybvyjwke 
13. Yemen: National Situation Report - July 2017 Yemen [Internet]. Relief Web. [cited2019, Jul30]. Available from: https://tinyurl.com/yaa7bpzf

14. Scrascia M, Pugliese N, Maimone F, Mohamud KA, Ali IA, Grimont PA, Pazzani C. Cholera in Ethiopia in the 1990s: Epidemiologic patterns, clonal analysis, and antimicrobial resistance. International Journal of Medical Microbiology. 2009 Jun 1;299(5):367-72.

15. BEYENE BB, Tumato $M$, Abera B, Maskai O, Luce R. Epidemiology of Acute Watery Diarrhea Outbreak and Challenges of Control-Afar, Ethiopia, 2009. International Journal of Medicine and Medical Sciences (ISSN: 2315-9844). 2014 Oct;1(10):162-9.

16. World Health Organization Global Task Force on Cholera Control. Overview of ending cholera: a global road map to 2030 [cited 2020 Jan 27]. Available from: https://tinyurl.com/y83vfv8w

17. Simane B, Beyene H, Deressa W, Kumie A, Berhane K, Samet J. Review of climate change and health in Ethiopia: status and gap analysis. Ethiopian Journal of Health Development. 2016;30(1):28-41.

18. Demographics of Ethiopia. In: Wikipedia [Internet]. 2020 [cited 2020 Jan 27]. Available from: https://inyurl.com/yabysv69

19. Ethiopia Area - Geography [Internet]. [cited 2020 Jan 27]. Available from: https://tinyurl.com/yb8j65tz

20. Ethiopia - Population density (people per sq. $\mathrm{km}$ of land area) [Internet]. [cited 2020 Jan 27]. Available from: https://tinyurl.com/ycp3kyy2

21. EHNRI, FMOH. Guideline on cholera outbreak management in Ethiopia. Ethiopian Health and Nutrition Research Institutes, $1^{\text {st }}$ (edn)2011. Available from: https://tinyurl.com/y7zepv9o

22. Federal Democratic Republic of Ethiopia Central Statistical Agency Population Projection of Ethiopia for All Regions at Woreda Level from 2014 - 2017 - Google Search [Internet]. [cited 2020 Jun 13]. Available from: https://tinyurl.com/ybgcsq4v

23. Bartels SA, Greenough PG, Tamar M, VanRooyen MJ. Investigation of a cholera outbreak in Ethiopia's Oromiya region. Disaster medicine and public health preparedness. 2010 Dec;4(4):312-7.

24. World Health Organization. International health regulations (2005). World Health Organization; 2008.

25. Sur D, Dutta P, Nair GB, Bhattacharya SK. Severe cholera outbreak following floods in a northern disrict of West Bengal. Indian Journal of Medical Research. 2000 Nov 1; 112:178.

26. Alkassoum SI, Djibo I, Amadou H, Bohari A, Issoufou H, Aka J, Mamadou S. The global burden of cholera outbreaks in Niger: an analysis of the national surveillance data, 2003-2015. Transactions of The Royal Society of Tropical Medicine and Hygiene. 2019 May 1;113(5):27380 .

27. Central Statistical Agency (CSA) [Ethiopia] and ICF. 2016. Ethiopia Demographic and Health Survey 2016. Addis Ababa, Ethiopia, and Rockville, Maryland, USA: CSA and ICF.

28. FMOH. Health and Health Related Indicators of 2015 DKT Ethiopia (DKT/E) - Family Planning and HIV in Ethiopia [Internet]. [cited 2020 Jun 13]. Available from: https://tinyurl.com/yd7ehpyj

29. WHO Global Health Observatory, Cholera case fatality ratio (\%), World Health Organization; [cited 2020 Jun 13]. Available from: https://tinyurl.com/y8pxq92q

30. Ingelbeen B, Hendrickx D, Miwanda B, van der Sande MA, Mossoko M, Vochten $\mathrm{H}$, et al. Recurrent cholera outbreaks, Democratic Republic of the Congo, 2008-2017. Emerging infectious diseases. 2019 May;25(5):856.

31. Field Epidemiology. Third Edition. Oxford, New York: Oxford University Press; 2008. 592

32. Abubakar A, Bwire G, Azman AS, Bouhenia M, Deng LL, Wamala JF, et al. Cholera epidemic in South Sudan and Uganda and need for international collaboration in cholera control. Emerging infectious diseases. 2018 May;24(5):883.

33. Maman Manzo L, Moumouni A, Issa I, Amadou A, Zanguina J, Ibrahim DD, et al. Cholera in Niger Republic: An Analysis of National Surveillance Data, 1991 - 2015. International Journal of Infection. 2017 Jul 24; In Press.

34. Mutonga D, Langat D, Mwangi D, Tonui J, Njeru M, Abade A, et al. National surveillance data on the epidemiology of cholera in Kenya, 19972010. The Journal of infectious diseases. 2013 Nov 1;208(suppl_1): S55-61.

35. Sauvageot D, Njanpop-Lafourcade BM, Akilimali L, Anne JC, Bidjada P, Bompangue D, Bwire G, et al. Cholera incidence and mortality in SubSaharan African sites during multi-country surveillance. PLoS neglected tropical diseases. 2016 May;10(5): e0004679.

DOI: http://dx.doi.org/10.4314/ejhs.v30i4.2 